\title{
TELEOLOGÍA Y CAUSALIDAD
}

Margarta Ponce

INSTITUTO de INVESTIGACIONES FLOSOFICAS Universidad Nacional autónoma de MÉxico

0. Introducción. Hay una relación estrecha entre los problemas de la teleología y la causalidad como lo muestra, por ejemplo, la complementariedad de la explicación teleológica y de la causal: ambas conforman el proceso explicativo, que consiste primeramente en inquirir sobre las causas de un hecho o de un fenómeno cuya actualidad o cuyo acontecer nos sorprende, y luego, una vez encontradas, comprenderlas precisamente como responsables de tal hecho o de tal fenómeno. ${ }^{1}$ Se complementan así la explicación causal, que destaca algunas de las condiciones antecedentes - llamadas "entidades funcionales" dentro de este contextode aquello que deseamos explicar, y la teleológica, que destaca las consecuencias -a su vez llamadas "fines".

La relación entre teleología y causalidad se pone de manifiesto cuando se ahonda en las similitudes y en las diferencias que presentan ambos tipos de explicación: surgen problemas como el planteado por la "Tesis de la singularidad" ["The Uniqueness Claim"] —formulada por W. Wimsatt en su manuscrito "Functional Organization and the Logic of Functional Analysis"-, la cual expresa la intuición de que puede especificarse solamente una función genuina respecto de algún fin determinado. Ahora bien, esta intuición reviste especial importancia en biología, donde es uno de los supuestos indispensables para definir y redefinir (según las exigencias de su evolución) los sistemas vivientes (Cfr. Wimsatt, Ibid.). Se manifiesta comúnmente en la tendencia a usar el artículo definido la en enunciados funcionales: se dice, $v$. $g r$., "la función de la clorofila en las plantas es permitirles realizar la fotosíntesis", y no "una de las funciones de..." $2 \mathrm{Y}$ las posibles ventajas

1 Esta tesis de la complementariedad de las explicaciones teleológicas y las causales es central en mi tratamiento de la teleología, expuesto en La explicación teleológica, IIF - UNAM (en prensa).

2 De manera más formal, suele expresarse o bien afirmando que la relación 'desempeña una función en' es asimétrica e irreflexiva, o bien tratando las jerarquias funcionales como estructuras de árbol (por ejemplo Wimsatt en el manuscrito mencionado). 
tanto pragmáticas como formales de tratar las funciones bajo el supuesto de que la Tesis de la singularidad es verdadera, parecen esfumarse por la aparente existencia de circuitos funcionales cerrados, ${ }^{3}$ ya que podrían especificarse entonces varias funciones; el tratamiento formal aludido conservaría únicamente un valor heurístico, pues no sería fiel a los hechos. Y si consideramos ahora que el estado que llamamos "fin" -en el ejemplo de la nota 3, 'la circulación de la sangre'- es siempre una consecuencia causal del fenómeno explicado teleológicamente, resulta que el contexto adecuado para tratar estos problemas de la teleología es el de la causalidad, afirmación que justificaré en lo que sigue, examinando luego los aspectos relativos a la noción ortodoxa de causa, y al status ontológico de causas y efectos.

1. Teleologia y causalidad. La afirmación de que algunos problemas de la teleología deben tratarse desde la perspectiva del de la causalidad se funda en el hecho - reconocido ampliamente tanto por científicos como por filósofos- de que los fines son consecuencias causales de las entidades funcionales. ${ }^{4}$ Efectivamente, biólogos, físicos y sociólogos utilizan los enunciados de función en sentido causal, como podemos corroborarlo en los textos siguientes $-o$ en cualquier otra muestra de literatura científica:

1) Las mitocondrias son organelos citoplásmicos que permiten respirar aeróbicamente a las células (Jenkins 1975, p. 121).

2) Debido a su masa tan pequeña [los electrones] poseen gran movilidad; se encuentran libres en algunas condiciones especiales y, por ello mismo, son capaces de ir de un cuerpo a otro, produciendo fenómenos como la conductividad eléctrica, la ionización, etc. (Mosqueira 1966, p. 121). ${ }^{5}$

3 Un caso de circuito funcional cerrado sería el siguiente: "una función del corazón es contribuir a la circulación de la sangre. Una función de la circulación de la sangre es contribuir al intercambio de substancias nutritivas y de desecho hacia, y de, todas las partes del organismo. Una función de esto es contribuir a la fuerza estructural de la caja torácica. La fuerza estructural de la caja torácica protege los órganos internos (incluyendo el corazón) de golpes externos que podrian dañarlos y evitar que realizaran su función. - En consecuencia, una función de la circulación de la sangre es ... f favorecer la circulación de la sangre!" (Wimsatt 1972, p. 43).

4 Es importante recordar aquí que en el contexto de mi tratamiento de la teleología, "fin" no debe tomarse en sentido psicológico, como meta de la acción intencional, sino en los más amplios (especificados en varias ocasiones, v. gr., en cap. 2, pp. 51-2 o en cap. 4, pp. 133-3, 142, de la obra mencionada en la nota 1) del estado a cuyo logro o mantenimiento contribuyen las adaptaciones biológicas o, simplemente, de las consecuencias a cuya luz comprendemos el fenómeno que los produce.

5 Considero que los anunciados (1) y (2) son funcionales porque en ellos ciertas 
3) El latido del corazón en los vertebrados tiene la función de hacer que la sangre circule por el organismo, proveyéndolos así de alimento, y recogiendo los productos de desecho [de las células] (Hempel 1959, p. 305).

Así, Hempel y también otros autores como Nagel, Lehman y Wimsatt reconocen y aprueban este uso causal de los enunciados funcionales en la ciencia. El primero de ellos sostiene, por ejemplo, que una entidad funcional, consistente en rasgos fenotípicos persistentes de alguna manera (como el latir del corazón o ciertos patrones de conducta),

tiene efectos que satisfacen alguna "necesidad" o "exigencia funcional" [el énfasis es mío] (Hempel 1965, p. 306).

de los sistemas en los cuales se dan. Nagel,

en la hipótesis de que una explicación teleológica siempre puede traducirse a una no teleológica equivalente (Nagel 1961, p. 421),

afirma que la diferencia entre ellas

es entonces comparable a la diferencia entre decir que $Y$ es un efecto de $X$, y decir que $X$ es una causa o condición de $Y$ (Ibid., p. 405).

Lehman, quien reconoce las dificultades inherentes a la noción de causa y quisiera eliminarla del concepto de función, hace notar, sin embargo, que

reemplazar el concepto de causa con otro más claro, digamos con el de condición suficiente, serfa cometer una injusticia con el uso hecho por el biólogo de los enunciados funcionales (1965, pp. 15-6).

$Y$, por su parte, Wimsatt señala que los usos más interesantes de "función", a saber, aquellos en que este término designa funciones de perspectiva, evaluativas o teleológicas, nos remiten al concepto de causa porque, según dichos sentidos,

entidades (las mitocondrias y los electrones respectivamente) se comprenden conectándolas con sus consecuencias y no con sus condiciones antecedentes, $y$, aunque no es usual en ciencias distintas de la biología o de las ciencias sociales, equivaldrían a: ( $\left.1^{\prime}\right)$ 'la función de las mitocondrias es permitir que las células respiren aeróbicamente' y $\left(2^{\prime}\right)$ 'la función de la masa tan pequeña de los electrones es permitir que se encuentren libres en algunas condiciones especiales, capacitándolos para...' - suponiendo que función no es un concepto evaluativo (Cfr., Ponce, Ibid., cap. 4). 
las funciones son consecuencias causales de la entidad funcional que satisface varias condiciones adicionales. Aun cuando dichas condiciones adicionales puedan conferir un status especial a las condiciones causales elegidas, no por ello estas funciones dejan de ser consecuencias causales (Wimsatt Ibid., p. 10).

Así, después de considerar los textos anteriores, podemos afirmar justificadamente que el contexto adecuado para discutir la Tesis de la singularidad y la posible existencia de circuitos funcionales cerrados es el causal. No hay manera de tratar el problema de la teleología sin tratar por lo menos los aspectos del de la causalidad mencionados antes (en p. 2 supra).

2. La noción ortodoxa de causa. Según la concepción ortodoxa o estricta de las causas - que, como veremos a continuación, resulta demasiado estrecha para el tratamiento fructífero de la causalidad en la filosofía y en la ciencia-, éstas, para poderse calificar como tales, deben ser externas al sistema en el cual actúan y de índole dinámica o productiva. Por ello, desde esta perspectiva tan exigente de la causalidad, que atañe al ámbito de operación de las causas y al tipo de entidades que deben ser referidas por los términos singulares o por las descripciones definidas configurantes de los enunciados causales, no sería posible sostener que los fines (tal como los hemos entendido) sean consecuencias causales de alguna entidad funcional. Y, por tanto, el contexto de la causalidad no sería el más adecuado para tratar el problema de la teleología.

Sin embargo, en un tratado de fisiología leemos lo siguiente:

4) La importancia [de los genes] estriba en su capacidad para controlar la formación de otras substancias dentro de la célula. Lo hacen mediante el denominado código genético. ... [tres palabras del código, GCG, UCU y GAA] son la causa de la colocación de tres aminoácidos, alanina, serina y ácido glutámico, en una molécula de proteína (Guyton 1971, p. 31).

y en un análisis de las explicaciones funcionales se afirma que

5) ... el color negro [del $98 \%$ de los organismos pertenecientes a la especie Biston betularia] cumple la función de camuflar a las palomillas cuando descansan en los árboles ennegrecidos [por el $s m o g]$, para que los pájaros que se alimentan de ellas no las descubran tan fácilmente. (Williams 1976, p. 40). 
En (4) el autor asigna un claro papel causal a ciertas partes del código genético - a varios ordenamientos especiales de las bases que constituyen las moléculas de DNA de los genes- respecto de la conformación y desarrollo del sistema en que se encuentran (una célula). En (5), si aceptamos que "cumplir la función de ..." implica "causar (parcial o totalmente) x", la autora asigna un papel causal a cierta coloración específica exhibida por un grupo de organismos. Pues bien, estos dos usos de la palabra "causa" serían inadecuados para quienes exigen que toda causa, para serlo, debe operar por "compulsión externa" (Bunge 1959, pp. 24-5) y, además, ser productiva en si misma. Dentro de esta rígida concepción de la causalidad, cosas tales como genotipos, organelos, subsistemas, etc., no pueden calificarse de "causas" debido a que forman parte de sistemas más inclusivos, y las causas deben ser agentes extrínsecos. $Y$ tampoco cosas como la temperatura, la masa, o en general las cualidades y las disposiciones podrían ser causas, ya que no poseen, en sí mismas, virtudes productivas (Bunge 1959, pp. 21-2).

La primera objeción que puede hacerse a la exigencia de que las causas deban ser factores extrínsecos à los sistemas dentro de los cuales operan, es que va contra los usos científicos - como se ve en los ejemplos (1), (2) y (4) - y filosófico - como es claro en los textos de Nagel, Wimsatt, Hempel y Williams, citados respectivamente en las páginas 4-6 supra - de "causa" y "función". Y estos usos no son arbitrarios en manera alguna, sino que se apoyan en pruebas empíricas: indudablemente los genotipos son causa (parcial) del estado y características peculiares de los organismos en que se encuentran; y en ciertas circunstancias una determinada coloración de la piel (el color negro en el caso de las palomillas Biston betularia) determina si los organismos que la manifiestan sobreviven o desaparecen. En consonancia con lo anterior, y sin examinar aquí las dificultades que conlleva el problema de identificar la causa de un suceso, podemos aplicar el criterio general empírico para demostrar que algún hecho o algún suceso, $c$, pueden llamarse legitimamente "causas" debido a que modifican o producen otros, $e$. Este criterio es operacional y consiste, por una parte (la parte de la necesidad), en suprimir o modificar la presunta causa. Si consecuentemente el efecto no se da, o se da de manera distinta, podemos considerar a $c$ causa de $e$-lo cual sucede en los ejemplos (4) y (5) que versan sobre modificaciones causadas por algo que forma parte de un sistema más inclusivo, y por una cualidad de la piel de ciertos organismos, respectivamente. Y, por otra parte (la de la suficiencia), en introducir dicha causa $c$; si como consecuencia de ello, $e$ se da, también podemos considerar a $c$ causa de $e .^{6}$

6 Aunque prima facie parece mucho pedir que, con el fin de considerar un hecho 
Otra objeción al requisito de que la causa deba ser un factor extrínseco consiste en la dificultad para encontrar un criterio general que determine en qué sistema no está incluida. De modo trivial, podemos decir que todas las llamadas "causas" pertenecen al sistema en el cual operan, pues todas forman parte del macrosistema que es el universo. Además, intuitivamente es aceptable que si un suceso $S_{1}$ causa otro suceso $\mathrm{S}_{2}$, ambos sucesos puedan formar parte de otro más inclusivo $\mathbf{S}$ : por ejemplo, si consideramos que $S_{1}$ es la acción de la energía solar y $S_{2}$ la supervivencia de las plantas verdes en la tierra, efectivamente $S_{1}$ es un factor extrínseco al sistema en que opera (la vida de las plantas verdes en la tierra). Pero si cambiamos nuestro punto de vista y consideramos el sistema más inclusivo formado por el sistema solar, $\mathbf{S}$, tanto $S_{1}$ como $S_{2}$ resultan dos de sus componentes, y la operación $S_{1}$ modifica de alguna manera la configuración de $\mathbf{S}$, lo cual sería un caso similar al de la acción del genotipo respecto de la célula y el organismo.

Por todo ello pienso que, en vez de exigir que las causas operen "por compulsión externa", debemos contentarnos con una exigencia más moderada, que bien puede ser la aristotélica de que nada sea su propia causa (Aristóteles Phys. 195a 5-10). Así quedaría a salvo cierta externalidad de la causa respecto de su efecto y, a la vez, desaparecería la inconsistencia entre este requisito y el uso común de "causa". El problema de que, según la estricta ortodoxia de la causalidad, los términos que se refieren a cosas que no poseen virtudes productivas en si mismas no deben figurar en enunciados causales, es un problema complejo cuyas raices se hallan, en parte, en la evolución histórica del concepto de causa y, en parte también, en que tales cosas, en apariencia no-productivas, están descritas inadecuadamente.

Conviene recordar brevemente que, de la filosofía clásica griega a Galileo, prevaleció la doctrina aristotélica sobre la causalidad. De acuerdo con ella, toda determinación era determinación causal, pues la palabra "causa" designaba tanto un agente dinámico y productivo que modifica o cambia a otra entidad ("causa eficiente"), como factores estructurales, composicionales o materiales; y, desde luego, designaba también el fin o "aquello con miras a lo cual" una cosa se hace (Aristóteles, Ibid., 194b 20-35, 195a 5). A partir de Galileo, el sentido de "causa" queda restringido al de "causa eficiente", es decir, se refiere ya sólo a entidades dinámicas que poseen virtudes generativas y productivas. En consecuencia, actualmente consideramos que no toda determinación es

o un suceso $c$, causas de otros, $e$, que los primeros deban ser tanto necesarios como suficientes para sus respectivos efectos, esto no resulta desmesurado si recordamos que la distinción necesidad/suficiencia tiene importancia sólo en el plano de la explicación, y que tiene que ver con la manera como se describan causa y efecto (Cfr., pp. 17-8, infra). 
determinación causal. Sin embargo, esta creencia al parecer universal, cobija en la práctica muy diversas actitudes y opiniones sobre lo que es una causa; desde la posición de Bunge que, según vimos, presupone la externalidad absoluta de la causa, además de su dinamismo y pro ductividad, hasta las de los otros autores que hemos mencionado y que son más flexibles. Esta disparidad de opiniones apunta hacia un aspecto sutil del problema: que todavía no acabamos de asimilar bien el concepto moderno de causa. De alguna manera, las otras causas aristotélicas asoman en la literatura cientifica y filosófica. Sin duda existe cierta nostalgia por los sentidos de "causa" que quedaron eliminados en la Edad Moderna. Dicha nostalgia se manifiesta, por un lado, en el renovado interés por el tema de la teleología y, por otro, en el uso intuitivo del término que se sigue aplicando a disposiciones, cualidades y factores estructurales. Parece haber una tendencia a reinsertar de algún modo estas olvidadas causas aristotélicas en nuestra noción de causa, y esta tendencia ha promovido (explícita o implícitamente) la búsqueda de nociones más comprehensivas que den cuenta de la producción de un resultado particular. Surge así, por ejemplo, la noción de "complejo causal", la cual permite afirmar que un suceso determinado resulta tanto de factores causales como de otro tipo de determinantes (Bunge Ibid., pp. 59-61). Es conveniente, pues, que entre las dificultades que entraña el análisis de la teleología dentro de un contexto causal, se tenga en cuenta aquella que representa esta evolución, inacabada aún, del concepto de causa.

Por mi parte, pienso que una posible solución a la dificultad de que pueden figurar en enunciados causales, disposiciones, estructuras peculiares, cualidades, etc. - las cuales aparentemente no poseen virtudes productivas-, consiste en describirlas adecuadamente, de manera que se presenten como entidades dinámicas $\mathrm{y}$, por ende, con capacidad de provocar cambios y modificaciones en otras cosas. Es decir, debemos describirlas de manera que cumplan con el dogma central de la ontología de la causación, a saber, que las entidades denominadas "causa" y "efecto" sean sucesos. -Lo cual, de paso, apoyaría mi tesis de que el enfoque correcto en la determinación de la causa es el epistemológico, è de la descripción. Así, la formulación correcta de (5) en contextos causales sería:

5') ... la ocurrencia del color negro [en el $98 \%$ de los organismos pertenecientes a la especie Biston betularia] cumple la función de... etcétera.

Muy probablemente los científicos se refieren también a sucesos de 
este tipo cuando hablan de cosas funcionales como un color, una forma determinada, etc., que, vale reiterar, no podemos eliminar a priori de la categoría de las causas.

3. La ontologia de la causalidad. Las cuestiones tratadas hasta ahora, siendo necesarias para mostrar qué fines y funciones deben tratarse dentro de un contexto causal, quedan sin embargo en la periferia del genuino problema de la ontología de las causas. Éste consiste en determinar qué clase de entidades son aquellas entre las cuales puede establecerse una relación de causa a efecto $y$, aunque sea superficialmente, hay que asomarnos a él, ya que no se le puede disociar por completo del de los aspectos pragmáticos de la causalidad, desde cuya perspectiva tendría sentido decir, por ejemplo, "no hay circuitos funcionales (causales) cerrados".

Aun antes de que Davidson analizara la forma lógica de los enunciados causales singulares como una simple relación diádica del tipo $\mathrm{C}$ $\left(e, e^{\prime}\right)$, y recalcara la importancia de distinguir las cuestiones de aquello que es una causa y la de los rasgos elegidos para describirla y, por tanto, entre

la cuestión de si un enunciado dice con verdad que un suceso causó otro, y la cuestión ulterior de si los sucesos están caracterizados de tal manera que podamos deducir, o inferir de alguna otra manera, de leyes u otro tipo de enunciados causales, que la relación era causal (Davidson 1967, p. 88),

se aceptaba que la ontología más adecuada de la causalidad debía ser una ontología de sucesos particulares. Sin embargo; esta cuestión, aparentemente resuelta, presenta varias dificultades: 1) en primer lugar, las opiniones están divididas no en cuanto a la aceptación de sucesos particulares, sino en cuanto a si lo que llamamos "causa" puede ser exclusivamente un suceso particular. Vimos ya que la literatura científica refleja lo que varios filósofos aceptan: que también sucesos genéricos, hechos y estados de cosas pueden entrar en una relación causal; 2) o bien, a veces los autores que aceptan con exclusividad una ontologia de sucesos para la causalidad, caracterizan éstos de manera que dentro de su concepto caben otras muchas cosas. Y, 3) aun dentro de una aparente ontología de sucesos, lo que finalmente está en juego son nuestras creencias sobre el tipo de entidades que consideramos tienen primacía desde un punto de vista ontológico: los objetos o el cambio; Heráclito o Parménides, que siguen oponiéndose a través de las distintas maneras de entender los sucesos. Otro interés que tienen estas cuestio- 
nes es que ilustran uno de los problemas más elusivos y complicados de la teleología y de la causalidad, el de la tenue frontera entre lo ontológico y lo epistemológico; el de la confusión entre estos planos, que según advierte Davidson en el párrafo citado, debe evitarse, distinguiendo entre examinar el significado de los enunciados causales singulares, y nuestra comprensión de la relación causal. Pero tanto nuestro aparato conceptual y lingüístico como nuestra tendencia a buscar explicaciones nos conducen con frecuencia a mezclar los dos planos.

Entre los autores que aceptan una ontología no sólo de sucesos, sino también de hechos, están Peacocke (1980, p. 60), Lewis y Mackie. Lewis, en "Causation" (1973), se limita al análisis de la causalidad entre sucesos, entre cosas como "relámpagos, batallas, conversaciones, impactos, paseos, muertes, touchdowns, caídas, besos", etc. (Lewis Ibid., p. 182). $\mathrm{Y}$, al advertir que se limitará a tales cosas, admite tácitamente que la causación puede darse también entre otras entidades, de las cuales no se ocupa. Mackie, en The Cement of the Universe (1974), hace una distinción importante: cuando nos preocupa mayormente la explicación, entonces consideramos que tanto causas como efectos son hechos, y no sucesos particulares (Ibid., p. 260). Por ejemplo, dice, el hecho de que Edipo se haya casado con su madre explica la tragedia subsiguiente de un modo en que no lo hace la descripción en términos de su matrimonio con Yocasta. Y, en consecuencia, distingue entre dos tipos de causas, una en el plano ontológico, que son los sucesos y que denomina "causa productora", y otra en el plano epistemológico que llama "causa explicadora". Esta última debe aludir a todos los rasgos que intervienen causalmente, o que son "causalmente importantes", en la ocurrencia de algún acontecimiento. Introduce así dos nociones muy útiles tanto para el análisis de la causalidad como para el de la teleología.

Mackie, además, caracteriza las causas como condiciones INUS, y en esta caracterización entremezcla —cayendo él mismo en la confusión señalada por Davidson respecto del ámbito donde tiene importancia la distinción necesidad/suficiencia- los planos ontológico y epistemológico de la causalidad. Según Mackie, el análisis de los enunciados causales revela la existencia de condicionales contrafácticos, mismos que se justifican en la inducción y en las regularidades correspondientes (Ibid., pp. 59-60). Y partiendo de la tesis de que un efecto puede resultar de diversas causas (tesis que no comparto pues creo que cuando esto sucede se debe a que tenemos una descripción incompleta del efecto), introduce en el análisis de ellas las nociones de condición necesaria y condición suficiente - desde el punto de vista no de sucesos particulares, sino de clases de sucesos. Transcribo este análisis, ya que es clásico en el tema: suponiendo que el universo es ordenado, podemos tener 
un par de proposiciones universales (aproximadamente) recíprocas [a saber,] 'P se sigue de todo (ABC o DHG o JKL) [cada mayúscula representa un tipo de suceso o de situación; ' $P$ ' representa el efecto que ocurre siempre que se da alguna conjunción de factores - por ejemplo, A, B y C, conjunción que se representa como 'ABC'- (y lo mismo representan ' $\mathrm{DGH}$ ' o 'JKL'), pero no cuando están presentes sólo algunos de esos factores] y 'todo $\mathrm{P}$ está precedido por (ABC o DGH o JKL)...

Entonces,... la fórmula compleja '(ABC o DGH o JKL)' representa una condición que es tanto necesaria como suficiente para que $\mathbf{P}$ ocurra: cada conjunción, tal como 'ABC', representa una condición que es suficiente, pero no necesaria para la ocurrencia de $P$. Además, $A B C$ constituye una condición suficiente minima: ninguno de sus conjuntos es redundante, es decir, ninguna parte de ella, como por ejemplo AB, es ella misma suficiente para $\mathbf{P}$. Pero cada factor aislado, por ejemplo A, no es ni una condición necesaria ni una suficiente para $\mathrm{P}$. $\mathrm{Y}$ sin embargo se relaciona claramente con $\mathbf{P}$ de una manera importante: es una parte insuficiente mas no-redundante de una condición innecesaria pero suficiente (Mackie, Ibid., pp. 61-2).

Este tipo de condición sería una condición INUS.

La prueba de que Mackie entremezcla los planos ontológico y epistemológico de las causas, es su creencia de que un resultado puede producirse a partir de diversas causas. Esta afirmación es incorrecta tratándose de sucesos particulares, pues cada suceso incluye una gran complejidad de factores que, en las circunstancias en que acaecen, los hacen suficientes y necesarios para la ocurrencia de otro suceso (efecto) particular. La afirmación cobra, en apariencia, mayor plausibilidad en un plano más abstracto, el de la explicación, en el cual las descripciones adecuadas, y en lo posible completas, son tan importantes. Sin embargo, sostener que la causa puede ser descrita sólo como condición suficiente para su efecto, indica que no se toma en cuenta el carácter complementario de las descripciones en términos de necesidad-suficiencia. Tal como Davidson lo señala ( $C f r$., p. 23 infra) si decimos que cierto tipo de suceso representa una condición suficiente pero innecesaria para la producción de otro, nos hace falta una mejor descripción del efecto. Si por lo contrario, consideramos que la causa es una condición necesaria pero insuficiente del efecto, lo que seguramente nos hace falta es una descripción más completa de la causa (Davidson, 1967, p. 89).

Kim, por su parte, también hace notar que el tratamiento de las causas en términos de condiciones es quizá más adecuado cuando se 
trata de nuestra comprensión de la causalidad y no de su ontologia. Dice además que en el análisis de Mackie subyace una confusión entre los sucesos y sus descripciones, confusión que se debe al uso que comúnmente se hace de oraciones completas y de frases nominales para designar sucesos (Kim, 1971, p. 56) —un ejemplo de oración completa sería "comenzó un incendio en una casa", y uno de frase nominal "el hundimiento del Titanic".

Estas expresiones, dice $\mathrm{Kim}$, deben considerarse "términos singulares que se refieren a sucesos particulares" y por tanto deben complementarse con "especificaciones cronológicas explícitas" (Kim, Ibid., p. 60).7

Kim sostiene asimismo que la ontología adecuada de la causalidad es la de sucesos, aunque caracteriza éstos de manera que su noción incluya aquello que entendemos por estados. Advierte que los sucesos no son entidades lingüísticas, sino que puede hablarse de ellos, referirse a ellos y describirlos. Tampoco serían proposiciones (es decir, entidades abstractas), sino entidades concretas limitadas espacio-temporalmente (Kim 1969, p. 198). Hasta aquí todo parece ir bien, mas añade luego que lo anterior también es verdadero de categorías parecidas como "estados, condiciones, procesos, y quizás también hechos" (Ibid., p. 198); entidades todas ellas que, salvo en el caso de los procesos (o secuencias de sucesos), nos parecen intuitivamente menos fuertes que los sucesos particulares, desde un punto de vista ontológico. Así, cuando aplica su noción de suceso a la causalidad, adolece del mismo defecto que critica a Mackie, pues entremezcla los planos ontológico y epistemológico a través de su preocupación por combinar el análisis en términos de necesidad y suficiencia de este autor, con un análisis más plausible del sentido de los juicios causales singulares (Kim, 1971, p. 59). Desea encontrar entidades que "posean tanto un elemento de generalidad como un elemento de particularidad", e impulsado por este deseo, caracteriza los sucesos como

la realización de propiedades en regiones espacio-temporales particulares o en objetos (si aceptamos algún tipo de ontología de substancias)... [estas entidades] llenan el expediente; ellas son generales en cuanto implican propiedades, y particulares en cuanto implican regiones particulares de espacio y tiempo, u objetos. En

7 No profundizaré en este problema semántico; sin embargo, recordemos que Davidson en "The Individuation of Events", afirma a su vez que también Kim confunde los planos ontológico y epistemológico, pues cae en el error de confundir hechos y sucesos. La tesis de Davidson es que las oraciones completas relativas a sucesos (por ejemplo "César murió"), están existencialmente cuantificadas y son generales, por lo cual no hay tal término singular que pueda referirse a un suceso. No así en el caso de las frases nominales, que sí se refieren a sucesos. 
consecuencia, consideramos que un suceso es la ejemplificación de una propiedad empírica por cierto objeto en tiempo dado (o alternativamente, en una región espacio-temporal; pero adoptaremos el primer enfoque);

finalmente, insiste en que

tal como se usa el término 'suceso' debe entenderse en sentido amplio, y referirse tanto a estados como a sucesos -en el sentido estricto de que implica cambios (Ibid., pp. 59-60).

Kim argumenta que esta tesis es connatural al lenguaje ordinario, pues las entidades que normalmente llamamos "sucesos" se designan mediante el uso de frases del tipo de "la muerte de Sócrates", o de "el hundimiento del Titanic". Y, efectivamente, el uso normal de estas frases en contextos causales y funcionales, por lo menos en la literatura científica, parece apoyar la tesis de Kim sobre la necesidad de caracterizar los sucesos de manera que, aun en la ontología de las causas, se manifieste un elemento de generalidad. Sin embargo, no podemos ignorar que el uso de "causa" o "entidad funcional" para designar hechos revela que la ciencia no está mayormente interesada en sucesos particulares, sino en tipos de sucesos, y las expresiones que en una lectura superficial aparentan ser enunciados singulares, causales o funcionales, por ejemplo,

6) La función de la clorofila en las plantas es permitir que éstas realicen la fotosíntesis (Nagel 1961, p. 403)

son en realidad explicaciones abreviadas como la siguiente:

6') Cuando las plantas se hallan en un medio provisto de agua, bióxido de carbono y luz solar, producen almidón; si las plantas no poseen clorofila, aun cuando tengan agua, bióxido de carbono y luz solar, no producen almidón; por tanto, las plantas contienen clorofila (Nagel Ibid., p. 403).8

8 En el texto, citado en $\left(6^{\prime}\right)$, faltaría la premisa "las plantas producen almidón". Pero dejando de lado estas minucias, para Nagel (6) "explica la presencia de la clorofila (cierta substancia $A$ ) en las plantas (en todo miembro $S$ de una clase de sistemas, que posee, cada uno, cierta organización $\mathrm{C}$ de partes componentes y de procesos). (6) explica esto declarando que, cuando se provee a una planta de agua, bióxido de carbono y luz solar (cuando $S$ se halla en cierto medio $E$, 'interno' y 'externo'), produce almidón (cierto proceso $P$ que tiene como resultado un producto definido, tiene lugar) sólo si la planta contiene clorofila. El enunciado generalmente conlleva, de manera tácita, la suposición de que sin almidón la planta no puede continuar sus actividades características, tales como crecer y reproducirse (no puede 
7) La carencia de un sistema precoz de alarma causó el desastre.

Si bien (según se desprende del análisis de Davidson aludido anteriormente) una ontología de sucesos particulares es la más adecuada para la causalidad, no podemos ignorar que tanto la caracterización que Kim hace de los sucesos, como aquella que Mackie hace de las causas, y el uso común de enunciados como (6) y (7) para designar causas, efectos, funciones o fines, surgen de nuestra tendencia a buscar explicaciones y a manejar generalidades. $Y$ esta tendencia, lo mismo que nuestras teorías e intereses, hacen difícil evitar confusiones como la tratada aquí. Además, los aspectos ontológico y epistemológico de la causalidad ( $y$ por ende de la teleología) se relacionan vía la verdad de los enunciados causales singulares, verdad que, en último término, se funda en nuestra creencia de que existe una ley (conocida o desconocida) de la cual ese enunciado es un caso. Una razón más de la dificultad de separar estos campos es que los problemas de la determinación de la causa y de la especificación de cadenas causales se plantean, y quizás también se resuelven, dentro de una perspectiva epistemológica, a cuya luz las afirmaciones de Mackie y de Kim que hemos visto cobran nuevo valor y utilidad.

Otro tratamiento clásico en el género es la propuesta de Davidson sobre el criterio de identidad de dos sucesos. Sostiene que la manera correcta de plantear el problema es en un nivel lingüístico, donde podemos preguntarnos cuándo son verdaderas ciertas oraciones de la forma " $\mathrm{a}=\mathrm{b}$ ", en las cuales suponemos que términos singulares que designan sucesos ocupan el lugar de "a" y "b" (Davidson 1969, p. 216). Como parte de sus objeciones a Kim, Davidson dice que oraciones como "Bruto mató a César" no se refieren a sucesos, porque según señalé antes, se hallan existencialmente cuantificadas y son generales respecto de los sucesos (Davidson Ibid., p. 221). $\mathrm{Y}$ en cuanto a las causas, afirma que

de hecho, los sucesos no son necesarios o suficientes como causas, sino los sucesos como descritos de un modo o de otro. Es verdad que no podemos inferir, del hecho de que el fósforo había sido frotado y de leyes causales plausibles, que el fósforo se encendió; nos va mejor si comenzamos con el hecho de que un fósforo seco fue frotado en presencia de oxígeno suficiente. No se sigue que

mantenerse a sí misma en cierto estado G); ... (Nagel 1961, p. 403). En esta aclaración de Nagel, ni la entidad funcional (la presencia de la clorofila), ni el fin (cierto estado $G$ ) aparecen como sucesos particulares. 
algo más que el frotamiento particular de este fósforo, que acaeció se requiera para causar su "encenderse" (Davidson Ibid., p. 224).

Davidson ilustra así la difusa frontera entre los aspectos ontológico y epistemológico de la causalidad. $Y$ en cuanto al criterio de identidad de los sucesos, dice que

los sucesos son idénticos sii tienen exactamente las mismas causas y efectos (Ibid., p. 231).

Debido a la ambigüedad de "causa", este criterio propuesto por $\mathrm{Da}$ vidson, en abstracto, parece correcto y plausible, pero en la práctica ofrece muchas dificultades porque, en la identificación de causas y cadenas causales, el sujeto juega un papel determinante, con su carga de teorías, intereses y limitaciones.

Ahora bien, volviendo a la cuestión clásica que subyace en todas estas discusiones, es decir, a la de qué clase de entidades tienen primacia ontológica, si los objetos o los sucesos (entendidos en sentido estricto), la posición de Kim es interesante pues se sitúa dentro de una ontologia substancialista que parecía superada en la ciencia actual. Su caracterización de sucesos permite concluir que los objetos tienen primacía. $\mathrm{Y}$ así, la relación causal se establecería, en último término, entre objetos, que son las entidades en las cuales puede ejemplificarse una propiedad.

El antecedente de Kim en la antigüedad es Aristóteles, aunque la interpretación de sus textos en este sentido es delicada. Por ello, recurriré aquí a la autoridad de Ross.

Aristóteles, en el libro VII de la Metafisica afirma que

la substancia es principio y causa (Met., 104la 8-10). Es aquello que buscamos cuando preguntamos "por qué una cosa se puede predicar de otra... Por ejemplo, ¿por qué truena? Esto equivale a '¿por qué se produce un sonido en las nubes?' ... Evidentemente buscamos la causa. Y ésta (hablando en abstracto) es la esencia, que en algunos casos es el fin, por ejemplo en el caso de una casa o de una cama, y en algunos casos es el primer motor; porque éste también es una causa. Pero mientras que la causa eficiente se busca en los casos de la génesis y la destrucción, la causa final se busca también en el caso de ser (Ibid., 20-35).

Ross interpreta el texto anterior reiterando que, en abstracto, la substancia es causa y fuente original, pero en concreto, las causas son o el fin o la causa eficiente (Ross, "Introduction", en Met., pp. cxi-cxii). Podría argüirse que Aristóteles, al hacer una diferencia entre la causa 
en abstracto y la causa en concreto, también da prioridad a los sucesos, por lo menos en lo concerniente a la causalidad. Sin embargo, Ross es formal y dice que, según el Estagirita, "la presencia de la esencia de la cosa concreta" es "la causa directa de su ser" (Ibid., p. cxi), y podemos concluir que, sin esa causa original, ningún otro tipo de causa podría ejercer su influjo sobre la causa en cuestión. ${ }^{9}$ Ahora resulta claro que Kim se sitúa en la línea aristotélica.

Dentro de la misma línea, Bunge denomina "entidad" o "cosa física" a los sistemas concretos (que pueden ser, por ejemplo, una onda de luz o una comunidad humana), es decir, a todos los existentes. $\mathrm{Y}$ sostiene que

Los acaecimientos o los procesos son lo que ocurre a, en y entre sistemas concretos,

añadiendo expresamente, contra la interpretación actual de la física, que

la doctrina metafísica según la cual las cosas no son más que conjuntos de acaecimientos, no tiene raíz científica (Bunge 1969, p. 720).

Lo interesante de estas afirmaciones es revelar que Bunge adopta, asimismo, la posición que da prioridad a los objetos, aunque, es justo reconocer, para él la expresión "sistemas concretos" se aplicaría tanto a un campo magnético como a una partícula.

La ciencia, hoy en día (según escuchamos en una conferencia de Jorge Bosch, sobre desarrollos recientes de la Física), parece respaldar la tesis de que los sucesos son las entidades primarias o los componentes básicos de nuestro universo. En consecuencia con esto, la teoría del "Big Bang" postula un suceso en el origen del cosmos; y la realidad física estaría constituida por combinaciones de sucesos elementales, como, por ejemplo, el choque de dos electrones. Sin embargo, debemos reconocer que esta idea es completamente antiintuitiva, pues no imaginamos el movimiento o el cambio aislados, sino que creemos más bien que algo es lo que cambia, se mueve, choca, etc. Así, resulta curioso que siendo indudablemente la posición que da primacía a los sucesos, la que mejor concuerda con la ontología exigida por el análisis davidsoniano de la forma lógica de enunciados causales singulares, Davidson mismo adopte - como es su costumbre - una actitud neutral y afirme que

9 La interpretación de Aristóteles que hace Wieland coincide en la tesis de que según el Estagirita, las causas y los efectos son propiamente los objetos, y sólo de manera secundaria podria decirse que los procesos "causan" o "sean causados". (Cfr. Wieland 1962, p. 150.) 
la mayoria de los sucesos se entienden como cambios en un objeto o substancia más o menos permanente. $Y$ hasta... parece plausible que el concepto de un suceso depende, en todos los casos, de la idea de un cambio en una substancia, a pesar del hecho de que en el caso de algunos sucesos no es fácil decir cuál es la substancia que sufre el cambio (Davidson 1969, p. 226).

Funda luego su tesis neutralista sobre las nociones de substancia y suceso en la noción de dependencia conceptual:

una oración como "John asestó el golpe" trata de dos particulares, John y el golpe. La distinción entre términos singulares y predicados no queda abolida. Más bien, el asestar se predica tanto de John como del golpe. Esta simetría en el tratamiento de las substancias y sus cambios refleja, creo, una simetría subyacente de dependencia conceptual. Las substancias deben su importancia especial en la empresa de la identificación, al hecho de que ellas subsisten a través del tiempo. Pero la idea de subsistencia es inseparable de la idea del subsistir bajo ciertos tipos de cambio - de posición, tamaño, forma, color, etc. Como podríamos esperar, los sucesos desempeñan con frecuencia un papel esencial en identificar una substancia. En consecuencia, si seguimos la pista del autor de Waverly o del padre de Annette, lo hacemos por medio de identificar un suceso, o escribir o engendrar. Ni la categoría de substancia, ni la categoría de cambio pueden concebirse separadamente una de la otra (Ibid., p. 227).

Lo cierto es que hay dificultad en decidirse por una u otra de las tesis anteriores. Por una parte, el sentido común y nuestra intuición nos inclinan hacia la tesis substancialista. Por otra, la ciencia, con sus desarrollos más actuales, parece apoyar la tesis de la primacía de los sucesos. Y, finalmente, cierta antipatía por las respuestas neutralistas nos llevan a desconfiar de las afirmaciones de Davidson. Sin embargo, bien puede ser que Davidson tenga razón y que los conceptos substancia-suceso sean correlativos. Es decir, que su naturaleza sea relacional y nos sirvan para estructurar ciertos elementos, componentes de lo que denominamos "realidad", cuya naturaleza desconocemos. En su status ontológico, substancia y suceso serían similares a causa y efecto, que también tienen una naturaleza relacional, y que nos servirían, asimismo, para estructurar las modificaciones que percibimos en lo que nos rodea.

En resumen, podemos concluir que dentro del problema de la causalidad, y a partir del intento por descubrir entre qué tipo de entidades puede establecerse una relación causal, se perfilan nítidamente - aunque su análisis está lejos de ser nítido- dos planos: el ontológico y el 
epistemológico; el de la "causa productora" y el de la "causa explicadora" (en palabras de Mackie). Desde la perspectiva del primero de esos planos, las causas pueden ser únicamente sucesos particulares; desde la del segundo, pueden contarse como causas los sucesos genéricos, los hechos y los estados de cosas - pues de todos ellos se pide generalmente una explicación. Este último representa el ámbito donde el sujeto, con sus intereses y modos de describir los sucesos, desempeña un papel decisivo en la configuración de las causas. Queda claro también que hoy en día la palabra "causa" designa, o bien 1) el agente productivo y dinámico que efectúa algún cambio en otra cosa, es decir, un suceso particular acotado espacio-temporalmente; o bien designa, 2) aquello que produce el efecto tal como está descrito; aquello que explica la peculiaridad del efecto que nos interesa, lo cual, precisamente, nos importa para la explicación.

\section{BIBLIOGRAFIA}

Aristóteles, Metaphysica. A revised text with Introduction and Commentary by W. D. Ross, Vol. I, Oxford University Press, Great Britain, 1948 (1a Ed. 1924).

- Metaphysica (Trad. W. D. Ross). En The Basic Works of Aristotle, Random House, New York, 1941.

- Physica. A revised text with Introduction and Commentary by W. D. Ross. Oxford, University Press, Great Britain, 1936.

- Physica (Trad. R. P. Hardie y R. K. Gaye). En The Basic Works of Aristotle, Random House, New York, 1941.

Bunge, Mario (1959), Causalidad (Trad. Hernán Rodríguez). Editorial Universitaria de Buenos Aires, Argentina, 1972 (3a Ed.).

Davidson, Donald (1967), "Causal Relations". En Sosa, E. (Ed.) (1975), Causation and Conditionals. Oxford University Press, Great Britain, 1980 (reimpresión).

- (1969), "The Individuation of Events". En Rescher, N. et al. (Eds.), Essays in Honor of Carl G. Hempel. D. Reidel Publ. Co., Dordrecht, Holland, pp. 216-34.

Guyton, Arthur (1971), Tratado de Fisiologia Médica (Trad. Alberto Folch y

Pí) Nueva editorial Interamericana, S. A. de C. V., México, 1975 (4a Ed.).

Hempel, Carl G. (1959), "The Logic of Functional Analysis". En Gross Llewellyn (Ed.), Symposium on Sociological Theory. Harper and Row, New York. - (1965), Aspects of Scientific Explanation and other Essays in the Philosophy of Science. The Free Press, New York.

Jenkins, John B. (1975), Genetics. Houghton Mifflin Company, Boston.

Kim, Jaegwon (1969), "Events and Their Descriptions: Some Considerations".

En Rescher, N. et al. (Eds.), Essays in Honor of Carl G. Hempel, D. Reidel Publishing Co., Dordrecht, Holland, pp. 198-215.

- (1971), "Causes and Events: Mackie on Causation". En Sosa, E. (Ed.), 
(1975), Causation and Conditionals. Oxford University Press, Great Britain 1980 (reimpresión), pp. 48-62.

Lehman, Hugh (1965), "Functional Explanation in Biology". En Philosophy of Science, 32, 1.

Lewis, David (1973), "Causation". En Sosa, E. (Ed.) (1975), Causation and Conditionals. Oxford University Press, Great Britain, 1980 (reimpresión), pp. 180-91.

Mackie, John L. (1974) The Cement of the Universe, Clarendon Press, Oxford, Great Britain.

Mosqueira, R. Salvador (1966), Física General, Ed. Patria, S. A., México, 1977 (6a. Ed.).

Nagel, Ernest (1961), The Structure of Science. Hackett Publishing Co., U. S. A., 1979 (2ạ Ed.).

Peacocke, Christopher (1979), Holistic Explanation. Action. Space, Interpretation. Oxford University Press, New York, U. S. A.

Ponce, Margarita, La Explicación Teleológica, IIF- UNAM (en prensa).

Ross, William D. (1948), "Introduction". En Aristóteles, Metaphysics, Vol. I. Oxford University Press.

Wieland, W. (1962), "The Problem of Teleology". En Articles on Aristotle, I. Science. Duckworth \& Co. Ltd., Great Britain, 1975, pp. 141-60.

Williams, Mary B. (1976), “The Logical Structure of Functional Explanations in Biology". En PSA 1976, I: 37-46.

Wimsatt, William C. (1972), "Teleology and the Logical Structure of Function Statements". Studies in the History and Philosophy of Science. 3, 1: 1-80, Great Britain. 